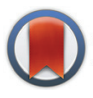

CrossMark

$\leftarrow$ click for updates

Cite this: Analyst, 2015, 140, 7522

Received 22nd September 2015, Accepted 7th October 2015

DOI: 10.1039/c5an01964h

www.rsc.org/analyst

\section{Electrochemical signatures of multivitamin mixtures}

\author{
A. M. Vinu Mohan, ${ }^{a}$ Barbara Brunetti, ${ }^{a, b}$ Andrea Bulbarello ${ }^{c}$ and Joseph Wang ${ }^{\star a}$
}

The ability of cyclic square wave voltammetry to identify distinct fingerprints of multiple vitamins, in a single voltammetric run, is demonstrated. This method represents an efficient alternative to more common techniques for fast screening of complex vitamin mixtures or commercial tablets due to its low cost, high speed and sensitivity.

\section{Introduction}

Vitamins are compounds essential for the normal growth and functioning of the human body. ${ }^{1}$ They are divided into watersoluble and fat-soluble. The well-known B complex and vitamin $\mathrm{C}$ belong to the first group. Many diseases are related to vitamin deficiency, consequently there is a growing interest in the development of reliable methods for their determination in many fields, especially food and supplements analysis. Official methods are generally based on microbiological assays $^{2}$ but the most commonly used are the chromatographic ones, ${ }^{3-8}$ despite the high cost of instrumentation and the low speed of analysis. Moreover, food matrices usually require laborious and time consuming steps for sample preparation. ${ }^{5,8-10}$ Electrochemical methods could be a valuable alternative, due to their high sensitivity, low cost and high speed. This last feature is particularly relevant when a fast screening of the samples is required. Voltammetric methods have been proposed for the determination of individual vitamins. ${ }^{11-16}$ However, just a few methods were proposed for analyses of mixtures of no more than three different vitamins, ${ }^{17-22}$ some of them using complex calibration systems. ${ }^{21,23}$ Among the newest electrochemical sensors, dis-

\footnotetext{
${ }^{a}$ Department of Nanoengineering, University of California San Diego, 9500 Gilman Drive \#0448, La Jolla, CA 92093, USA. E-mail: josephwang@eng.ucsd.edu; Fax: +1 (858) 534 9553; Tel: +1 (858) 2460128

${ }^{b}$ DeFENS, University of Milan, Via Celoria 2, I-20133 Milan, Italy

${ }^{c}$ DSM Nutritional Products Ltd, Wurmisweg 576, CH-4303 Kaiseraugst, Switzerland
}

posable screen-printed electrodes (SPEs) are becoming more and more popular. ${ }^{24-31}$ This is because of their low cost, high reproducibility and absence of tedious cleaning procedures. Appropriate modifying components can be incorporated into the carbon ink or deposited onto the electrode strip surface, ${ }^{32-35}$ increasing selectivity and/or sensitivity.

The present work is aimed at demonstrating the ability to measure multiple vitamins and obtain distinct signatures of complex mixtures such as supplement tablets using cyclic square wave voltammetry (C-SWV) in connection to disposable SPEs. C-SWV is a recently introduced electrochemical protocol $^{36,37}$ that is based on the combination of oxidative and reductive square-wave voltammetric scans presented together in a cyclic manner. It has also been reported as particularly effective in providing distinct fingerprints of complex mixtures, as was illustrated for nitro-containing explosives $^{36}$ and metal/organic propellant constituents of gunshot residues. ${ }^{37}$ In the following sections we will demonstrate the applicability of C-SWV to mixtures of multiple vitamins such as multivitamin tablets and its ability to obtain rich qualitative information in a very short time. Such an ability offers considerable promise towards rapid screening and quality control of vitamins in centralized and decentralized settings.

\section{Experimental}

\section{Chemicals and samples}

All reagents, purchased from Sigma-Aldrich Co (St. Louis, MO, USA) were of analytical grade and used as received. Carbon inks were obtained from the Gwent group (C2050425D1; Pontypool, UK); E3449 from Ercon Inc (Wareham, MA, USA) and IDH 1398694 from Acheson Inc (Woodbury, CT, USA). Distilled 18.2 $\mathrm{M} \Omega$ water was used in all the experiments.

Stock solutions of vitamins $\mathrm{B}_{2}, \mathrm{~B}_{6}$ and $\mathrm{C}$ were prepared daily using pH 6.5 phosphate buffer solution (PBS) as a sup- 
porting electrolyte. Vitamin $\mathrm{B}_{1}$ and $\mathrm{B}_{12}$ stock solutions were prepared in a $0.1 \mathrm{M} \mathrm{NaOH}$ solution and a $0.1 \mathrm{M}$ ethylenediaminetetraacetic acid (EDTA) solution, respectively. The mixture of vitamins was prepared using $1 \mathrm{mM}$ each of vitamins $\mathrm{B}_{1}, \mathrm{~B}_{12}$ and $\mathrm{C}, 0.1 \mathrm{mM}$ of vitamin $\mathrm{B}_{2}$ and $0.5 \mathrm{mM}$ of vitamin $\mathrm{B}_{6}$. The solution $\mathrm{pH}$ was adjusted to 9 with $\mathrm{NaOH}$.

The two different multivitamin tablet samples (Centrum ${ }^{\circledR}$ Silver ${ }^{\circledR}$ for men and One daily $\left.{ }^{\circledR}\right)$ were purchased at a local pharmacy. For every analysis, approx. half portion of the tablet $(1 \mathrm{~g})$ was dissolved in $10 \mathrm{~mL}$ of $\mathrm{pH}$ 6.5 PBS and filtered with Whatman filter paper (Grade 1) to obtain a clear solution. This solution was diluted ten times with PBS and then used for the electrochemical analyses.

\section{Apparatus}

A model 1232 potentiostat ( $\mathrm{CH}$ Instruments, Austin, TX, USA) and an Emstat electrochemical analyzer (Palmsens, The Netherlands), both connected to a PC, were employed for the voltammetric experiments. The measurements were conducted using commercial and in-house fabricated screenprinted electrodes (SPEs). The three-electrode cell configuration of the in-house fabricated SPEs consisted of working (3 $\mathrm{mm}$ diameter) and counter carbon electrodes and a $\mathrm{Ag} /$ $\mathrm{AgCl}$ pseudo-reference electrode. The carbon inks were screen-printed using an MPM-SPM semi-automatic screenprinter (Speedline Technologies, Franklin, MA) on a flexible polyethylene terephthalate (PET) substrate cured at $100{ }^{\circ} \mathrm{C}$ for $15 \mathrm{~min}$ in a convection oven. Thereafter, the $\mathrm{Ag} / \mathrm{AgCl}$ ink was screen-printed on the PET substrate and cured at $90{ }^{\circ} \mathrm{C}$ for $15 \mathrm{~min}$. The SPEs were pretreated by applying a $1.2 \mathrm{~V}$ potential for $10 \mathrm{~min}$ in a saturated $\mathrm{Na}_{2} \mathrm{CO}_{3}$ solution. ${ }^{38,39}$ It is widely recognized that this electrochemical pre-treatment enhances the electrochemical activity of SPE, ${ }^{38,39}$ since the binder present in the ink hinders the electron transfer kinetics.

Commercial SPEs have a three-electrode configuration consisting of DRP-110SWCNT screen-printed electrochemical sensors (DropSens, Oviedo, Spain). The working electrode (4 mm diameter) was a carbon electrode modified with singlewalled carbon nanotubes functionalized with carboxyl groups. It is printed with a carbon counter electrode and a silver pseudo-reference electrode. A DropSens cable connector (ref. CAC) was used to connect the sensors to the electrochemical analyzer.

The measurements were performed with a $60 \mu \mathrm{L}$ sample drop onto the electrode surface.

A conventional cell equipped with a standard glassy carbon disk electrode (3 mm diameter), an $\mathrm{Ag} / \mathrm{AgCl}$ reference electrode (both from $\mathrm{CH}$ Instruments) and a platinum counter electrode was also used for comparison purposes. Before each analysis, the glassy carbon electrode (GCE) was mirror polished with alumina slurry. The residual polishing material was removed by ultrasonication in a water bath.

All the experiments were conducted at room temperature $\left(22 \pm 2^{\circ} \mathrm{C}\right)$.

\section{Procedures}

Cyclic voltammetry (CV) and C-SWV analyses were performed at various working electrodes. Cyclic voltammograms were recorded from $-1.0 \mathrm{~V}$ to $+1.0 \mathrm{~V}$, then back to $-1.0 \mathrm{~V}$, at 0.05 $\mathrm{V} \mathrm{s}^{-1}$ scan rate, potential step $0.001 \mathrm{~V}$. All SWV scans were performed at frequency $10 \mathrm{~Hz}$, amplitude $0.025 \mathrm{~V} \mathrm{~s}^{-1}$ and potential step $0.004 \mathrm{~V}$. The anodic SWV scan was recorded from $-0.1 \mathrm{~V}$ to $+1.0 \mathrm{~V}$ and subsequently the cathodic SWV from $+0.1 \mathrm{~V}$ to $-1.0 \mathrm{~V}$. Both the scans were presented together in a cyclic manner (C-SWV) in one plot by using Origin v. 8.6 software.

\section{Results and discussion}

In this paper, both commercial and in-house fabricated screen-printed electrodes were evaluated. Different kinds of inks, namely Ercon, Acheson and Gwent, were used for the assembly of in-house fabricated SPEs while the commercial SPES (SWCNT-SPE) were characterized by the presence of single-walled carbon nanotubes functionalized with carboxyl groups.

To highlight the features of the SPEs, their voltammetric behavior was compared with that of a conventional GCE. The results obtained analyzing a mixture of vitamins at both kinds of electrodes (GCE and in-house fabricated SPE with Ercon ink) are shown in Fig. 1. This figure compares the cyclic voltammetric signatures for a mixture of five vitamins with the corresponding C-SWV patterns.

As highlighted in Fig. 1, C-SWV provides clear qualitative signatures of the vitamins, since it combines the distinctive highly sensitive and low-background response of SWV with the information about the reaction reversibility and qualitative information typically provided by cyclic voltammetry. C-SWV has been reported recently as a very effective and rapid way to obtain fingerprints of complex mixtures of explosives ${ }^{36}$ and gunshot residues. ${ }^{37}$

Regarding the redox behavior of vitamins, the observed voltammetric pattern is mostly in agreement with previous literature findings. As can be seen, the most noticeable difference between the GCE and the SPE is the absence (in the explored potential range) of the vitamin $\mathrm{B}_{12}$ oxidation peak at the GCE. On the contrary, at the SPE, it could be seen at $-0.9 \mathrm{~V}\left(\mathrm{a}, \mathrm{a}^{\prime}\right)$ as a reversible system separated from the $B_{2}$ pattern, centered at $-0.6 \mathrm{~V}\left(\mathrm{~b}, \mathrm{~b}^{\prime}\right)$. Vitamin $\mathrm{B}_{12}$ redox behavior is related to the presence of redox active $\mathrm{Co}(\mathrm{II}) / \mathrm{Co}(\mathrm{III})$ in the moiety and it is characterized by a complex mechanism. ${ }^{15}$ Also vitamin $\mathrm{B}_{2}$ displays a reversible reduction process, ${ }^{40}$ but in this case it is visible at both the electrodes.

Another difference is noticeable comparing the anodic square wave voltammograms, since at the GCE a peak (c) relevant to vitamin $B_{1}$ is also present, not detectable at the SPE, while the corresponding reduction peak $\left(c^{\prime}\right)$ is more marked at the SPE. The oxidation of vitamin $\mathrm{B}_{1}$ has already been studied in alkaline medium and it is a two-electron process. ${ }^{14}$ As is well known, ${ }^{41}$ vitamin $\mathrm{C}$ electrochemical oxidation is an irre- 

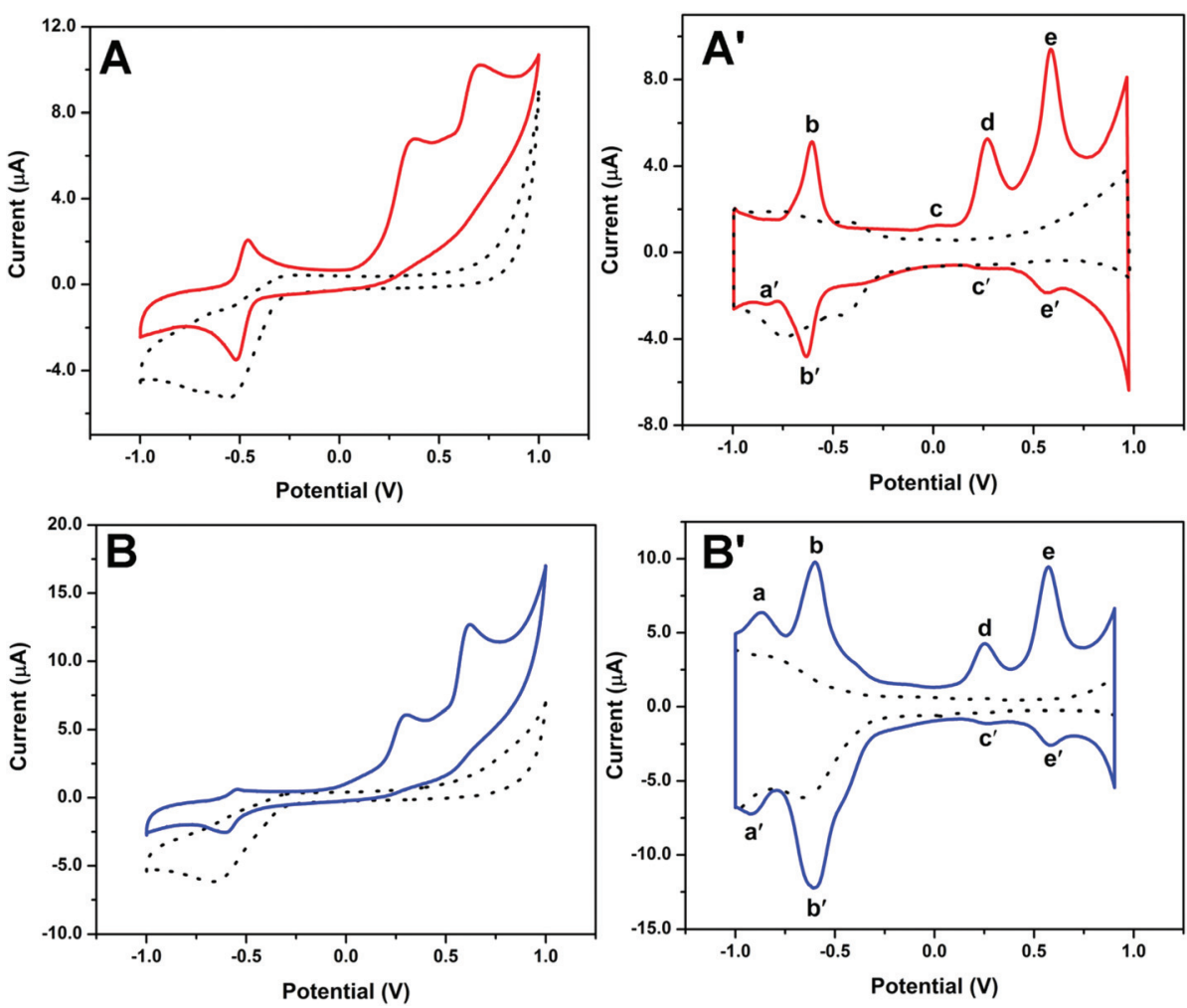

Fig. 1 Comparison of cyclic (A, B) and cyclic square wave $\left(A^{\prime}, B^{\prime}\right)$ voltammograms of the mixture of vitamins $\left(1 \mathrm{mM}\right.$ each of vitamin $B_{1}$, vitamin $C$, vitamin $B_{12} ; 0.1 \mathrm{mM}$ vitamin $B_{2}$ and $0.5 \mathrm{mM}$ vitamin $\left.B_{6}\right)$ at the bare GCE (A, $\left.A^{\prime}\right)$ and at the in-house fabricated SPE (Ercon ink) (B, $\left.B^{\prime}\right)$. Dotted line: blank solution. Voltammetric parameters: $C V$ scan rate: $0.05 \mathrm{~V} \mathrm{~s}^{-1}$; SW amplitude: $0.025 \mathrm{~V}$, SW frequency: $10 \mathrm{~Hz}$.

versible process. The relevant peak (d) is observed at about 0.25 $\mathrm{V}$ both at the GCE and SPE. The vitamin $\mathrm{B}_{6}$ cyclic voltammogram is characterized by an anodic peak in the forward step and by the absence of any peak on the reverse scan, as already reported at similar SPEs. ${ }^{13}$ However, the cathodic SWVs show a peak at about $0.6 \mathrm{~V}\left(\mathrm{e}^{\prime}\right)$. This finding is not surprising, considering the complexity of pyridoxine multi-step/multi-electron reactions that could take place. ${ }^{23,42,43}$ The process is also $\mathrm{pH}$-dependent due to complex distribution of species resulting from acid-base and hydration equilibria. Since redox behavior of all other vitamins is also strongly dependent on the solution $\mathrm{pH}$, preliminary experiments were performed to choose the best medium. The results allowed choosing $\mathrm{pH} 9$ at which the best compromise between sensitivity and peak separation is achieved.

Regarding the choice of the ink for the assembly of inhouse fabricated SPEs, a wide range of commercial formulations, suitable for screen-printing onto planar substrate materials, can be used for mass production of low-cost sensor strips. Carbon inks are particularly attractive since the resulting SPEs are of relatively low cost, and offer low background currents and broad potential windows. The exact ink formulation is regarded by the manufacturer as proprietary information. Differences in the ink composition may strongly affect the electron transfer ability and overall analytical performance of the resulting sensors. ${ }^{44}$ The formulations tested in this work were previously studied using various benchmark redox systems. ${ }^{44}$ The results showed that substantial differences in the electrochemical behaviors toward different compounds can be achieved, especially regarding the peak separation. In the present case, the best results were obtained with the Ercon formulation. As it is clearly illustrated in Fig. 2, the SPE obtained with this ink displays the highest sensitivities between the in-house fabricated sensors. However, commercial SPE modified with single-walled carbon nanotubes functionalized with carboxyl groups (SWCNT-SPE) showed a further increase in the peak current height and a lower oxidation potential. This effect could likely be due to the well-known catalytic effect of carbon nanotubes. ${ }^{35}$

Based on the obtained results, the following analyses of real samples were carried out using the SWCNT-SPE that showed the appealing analytical features above mentioned. The tested samples consisted of multivitamin supplement tablets of two different brands. As shown in Fig. 3, welldefined qualitative signatures of the vitamins are evident for both tablets. The compositions of the two samples look very similar, except for the higher anodic peak of vitamin $\mathrm{B}_{1}(\mathrm{~b})$ in the "One daily" tablet (Fig. 3A). This finding is in good agreement with the values declared by the manufacturer on the package, since this formulation reports a higher amount of vitamin $\mathrm{B}_{1}$. Two cathodic waves for this vitamin (b, $\mathrm{b}^{\prime}$, and $\left.\mathrm{b}^{\prime \prime}\right)$ 


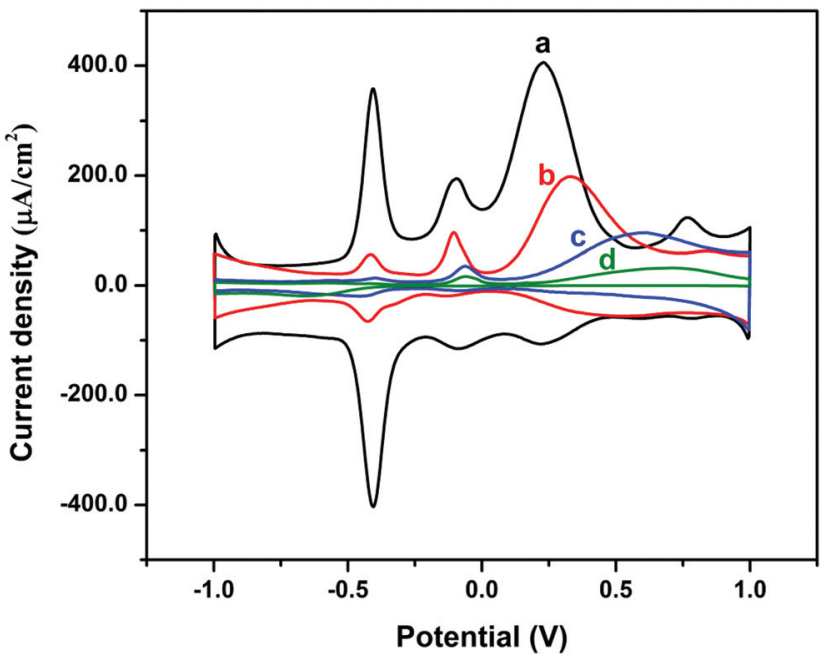

Fig. 2 Cyclic square wave voltammograms of "One Daily" multivitamin tablet at the SWCNT-SPE (a) and at the in-house fabricated SPEs (from different printing inks such as Ercon (b), Acheson (c) and Gwent (d)). Voltammetric parameters, as in Fig. 1.

are also visible and well separated from the abundant vitamin $\mathrm{C}$ signature at $0.23 \mathrm{~V}$ (c). As can be seen, the C-SWV yields a well-defined and sensitive vitamin $B_{2}$ redox couple $\left(a, a^{\prime}\right)$, centered at $-0.4 \mathrm{~V}$. Also, the vitamin $\mathrm{B}_{6}$ redox pairs are presented at $0.77 \mathrm{~V}\left(\mathrm{~d}, \mathrm{~d}^{\prime}\right)$. The redox peak for vitamin $\mathrm{B}_{12}$ is not visible due to its significantly lower concentration as compared with the other supplements in both tablets, as noted on the packages.

\section{Conclusion}

For the first time, the capability of a voltammetric method to identify simultaneously, in a single run, multiple vitamins was demonstrated. In particular, the ability of cyclic square-wave voltammetry to generate distinct electrochemical signals for vitamins $\mathrm{B}_{12}, \mathrm{~B}_{1}, \mathrm{~B}_{2}$ and $\mathrm{B}_{6}$ as well as the ubiquitous vitamin $\mathrm{C}$ was shown. The cyclic square-wave voltammetric route provides enriched information content with well-defined and substantially separated qualitative signatures for different vitamins, compared to the analogous cyclic voltammograms. Such improvements reflect the distinctive sharp and highly sensitive response and low background current of SWV. Since the whole voltammetric scan requires less than a minute to be performed, this method represents a valuable alternative to standard techniques for fast screening and initial quality control of complex matrices such as supplement tablets and food samples. Coupled with its high speed and simplicity, C-SWV at SPE strips offers considerable promise for decentralized quality control applications in relevant settings and scenarios.
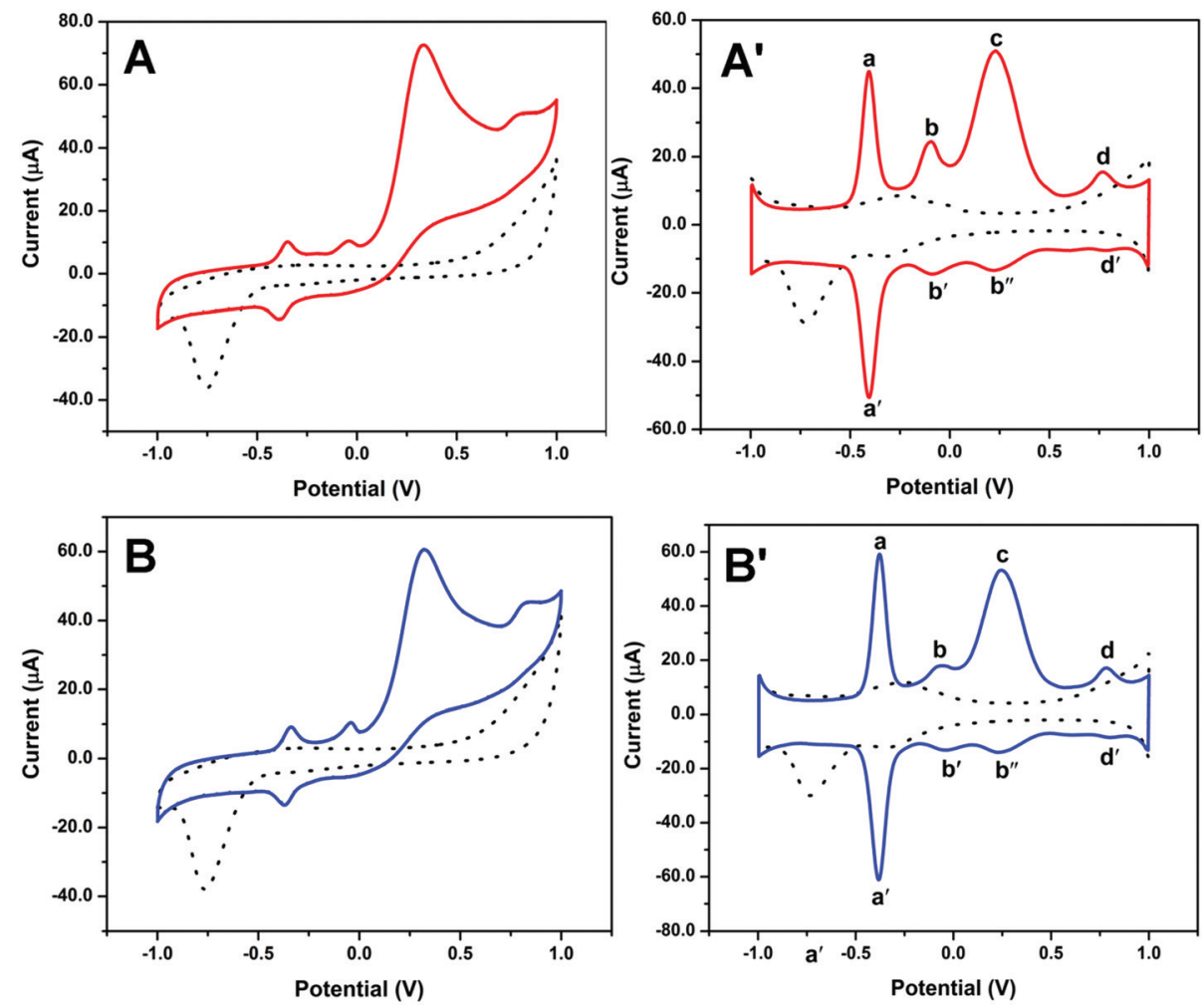

Fig. 3 Comparison of cyclic (A, B) and cyclic square-wave (A', B') voltammograms of multivitamin samples: 'One Daily' tablet (A, $A$ ') and 'Centrum ${ }^{\circledR}$ Silver $\AA^{\prime}$ tablet $\left(B, B^{\prime}\right)$ at the commercial SWCNT-SPE. Voltammetric conditions, as in Fig. 1. 


\section{Acknowledgements}

This work was supported from DSM Nutritional Products Ltd, Switzerland. B. Brunetti acknowledges COFIN 2010-2011 (MIUR, 2010AXENJ8_002) for sponsoring her visit to UCSD.

\section{References}

1 G. F. M. Ball, Vitamins in foods: analysis, bioavailability, and stability, Taylor \& Francis, Boca Raton, USA, 2006.

2 C. J. Blake, Anal. Bioanal. Chem., 2007, 389, 63-76.

3 A. Gliszczynska-Swigło and I. Rybicka, Food Anal. Methods, 2015, 8, 139-146.

4 E. Nurit, B. Lyan, A. Piquet, G. Branlard and E. PujosGuillot, Anal. Bioanal. Chem., 2015, 407, 3471-3479.

5 M. M. Phillips, Anal. Bioanal. Chem., 2015, 407, 2965-2974.

6 I. Marquez-Sillero, S. Cardenas and M. Valcarcel, J. Chromatogr. A, 2013, 1313, 253-258.

7 P. Jin, L. Xia, Z. Li, N. Che, D. Zou and X. Hu, J. Pharmaceut. Biomed. Anal., 2012, 70, 151-157.

8 J. H. Suh, D-H Yang, B. K. Lee, H. Y. Eom, U. Kim, J. Kim, H. Lee and S. B. Han, Bull. Korean Chem. Soc., 2011, 32, 2648-2656.

9 S. Ndaw, M. Bergaentzle, D. Aoude-Werner and C. Hasselmann, Food Chem., 2000, 71, 129-138.

10 Analytical Methods Committee, Analyst, 2000, 125, 353360.

11 I. P. Antal, Ya. R. Bazel and Zh. A. Kormosh, J. Anal. Chem., 2013, 68, 565-576.

12 S. M. Cottica, J. Nozaki, H. S. Nakatani, C. C. Oliveira, N. E. de Souza and J. V. Visentainer, J. Braz. Chem. Soc., 2009, 20, 496-501.

13 B. Brunetti and E. Desimoni, J. Food Compos. Anal., 2014, 33, 155-160.

14 J. Oni, P. Westbroek and T. Nyokong, Electroanalysis, 2002, 14, 1165-1168.

15 N. Yang, Q. Wan and X. Wang, Electrochim. Acta, 2005, 50, 2175-2180.

16 J. Bai, J. C. Ndamanisha, L. Liu, L. Yang and L. Guo, J. Solid State Electrochem., 2010, 14, 2251-2256.

17 B. Bas, M. Jakubowska and L. Gorski, Talanta, 2011, 84, 1032-1037.

18 S. B. Revin and S. A. John, Electrochim. Acta, 2012, 75, 35-41.

19 H-Y Gu, A-M Yu and H-Y Chen, Anal. Lett., 2001, 34, 23612374.

20 T. Nie, K. Zhang, J. Xu, L. Lu and L. Bai, J. Electroanal. Chem., 2014, 717-718, 1-9.
21 R. C. Barthus, L. H. Mazo and R. J. Poppi, J. Pharmaceut. Biomed. Anal., 2005, 38, 94-99.

22 A. Baghizadeh, H. Karimi-Maleh, Z. Khoshnama, A. Hassankhani and M. Abbasghorbani, Food Anal. Methods, 2015, 8, 549-557.

23 S. R. Hernandez, G. G. Ribero and H. C. Goicoechea, Talanta, 2003, 61, 743-753.

24 R. O. Kadara, N. Jenkinson and C. E. Banks, Sens. Actuators, $B, 2009$, 138, 556-562.

25 J. P. Metters, R. O. Kadara and C. E. Banks, Analyst, 2011, 136, 1067-1076.

26 O. Dominguez Renedo, M. A. Alonso-Lomillo and M. J. Arcos Martinez, Talanta, 2007, 73, 202-219.

27 A. Hayat and J. L. Marty, Sensors, 2014, 14, 1043210453.

28 A. Morrin, A. J. Killard and M. R. Smyth, Anal. Lett., 2003, 36, 2021-2039.

29 I. Ojeda, M. Moreno-Guzman, A. Gonzalez-Cortes, P. YanezSedeno and J. M. Pingarron, Analyst, 2013, 138, 42844291.

30 J. Hood, R. O. Kadara, D. K. Kampouris and C. E. Banks, Analyst, 2010, 135, 76-79.

31 K. Kumar Mistry, K. Layek, A. Mahapatra, Ch. RoyChaudhuri and H. Saha, Analyst, 2014, 139, 2289.

32 D. W. Hatchett and M. Josowicz, Chem. Rev., 2008, 108, 746-769.

33 M. Iwamoto, S. Tokonami, H. Shiigi and T. Nagaoka, Res. Chem. Intermed., 2009, 35, 919-930.

34 P. Fanjul-Bolado, P. Queipo, P. J. Lamas-Ardisana and A. Costa-Garcia, Talanta, 2007, 74, 427-433.

35 J. Wang, Electroanalysis, 2005, 17, 7-14.

36 M. Galik, A. M. O'Mahony and J. Wang, Electroanalysis, 2011, 23, 1193-1204.

37 M. Vuki, K-K Shiu, M. Galik, A. M. O'Mahony and J. Wang, Analyst, 2012, 137, 3265-3270.

38 G. Cui, J. H. Yoo, J. S. Lee, J. Yoo, J. H. Uhm, G. S. Cha and H. Nam, Analyst, 2001, 126, 1399-1403.

39 J. Wang, M. Pedrero, H. Sakslund, O. Hammerich and J. Pingarron, Analyst, 1996, 121, 345-350.

40 S. Cakir, I. Atayman and O. Cakir, Microchim. Acta, 1997, 126, 237-240.

41 A. M. Pisoschi, A. Pop, A. I. Serban and C. Fafaneata, Electrochim. Acta, 2014, 121, 443-460.

42 A. G. Crevillen, M. Pumera, M. C. Gonzalez and A. Escarpa, Electrophoresis, 2008, 29, 2997-3004.

43 M. L. Wang, Y. Y. Zhang, Q. J. Xie and S. Z. Yao, Electrochim. Acta, 2005, 51, 1059-1068.

44 J. Wang, B. M. Tian, V. B. Nascimento and L. Angnes, Electrochim. Acta, 1998, 43, 3459-3465. 